\title{
Artificial Cough Maneuvers: A New Method of Secretion Clearance?
}

Secretions above and below the cuff of an endotracheal tube (ETT) are pathogenic sources that may result in nosocomial infections and related complications. ${ }^{1}$ Efficient removal of these secretions has been a hot topic for the past 25 years. In this issue of RESPIRATORY CARE, Zanella et $\mathrm{al}^{2}$ presented an innovative system to expel the secretions located below an ETT cuff out of the trachea by using an artificial cough maneuver in an in vitro trachea model as well as in a brain-dead swine model.

Intubation impairs normal physiologic functions such as cough and swallow that aid in the prevention of aspiration. The spindle shape of the vocal cords and the cylindrical structure of an ETT do not allow for a tight seal. Therefore, it is difficult to prevent secretions from the oral cavity and/or gastric contents from leaking through the latent gaps between the glottis and the ETT. This may result in complications, for example, ventilator-associated pneumonia (VAP), ${ }^{1}$ which is one of the most common nosocomial infections and is associated with a high mortality rate. ${ }^{3}$

Countless efforts have been made to seek solutions to prevent VAP, ${ }^{4-7}$ including placing patients in the Semi-Fowler position (to reduce gastric reflux $)^{5}$; selective digestive decontamination, oral suctioning and oral hygiene (to reduce the quantity and density of the pathogens in the gastric and oral secretions $)^{5-7}$; and close monitoring and maintenance of ETT cuffs (to minimize microaspiration by stopping the subglottic secretions from leaking around the cuff). ${ }^{4,8}$ However, these methods are not likely to prevent all secretions from accumulating above the ETT cuff. Once accumulated, secretions can easily fall into the lower airways if the ETT is deflated for repositioning or extubation.

Because these subglottic secretions pose a threat to patients on mechanical ventilation, subglottic secretion drainage is warranted and seems to play an important role in VAP prevention. ${ }^{4}$ More than 20 randomized controlled trials and 6 meta-analyses have shown that subglottic secretion drain-

\footnotetext{
Mr Scott has disclosed a relationship with Ventec Life Systems. The remaining authors have disclosed no conflicts of interest.

Correspondence: Jie Li MSc RRT RRT-NPS RRT-ACCS, Division of Respiratory Care, Department of Cardiopulmonary Sciences, Rush University Medical Center, 1653 W Congress Pkwy, Chicago, IL 60612. E-mail: Jie_Li@rush.edu.
}

DOI: $10.4187 /$ respcare.07000 age is a cost-effective method to reduce the incidence of VAP, especially for patients who need invasive ventilation for $>48 \mathrm{~h} .{ }^{8}$ However, subglottic secretion drainage has limitations in clinical practice, including: (1) a special tube is required, and, if not initially placed, the exchange of the conventional ETT to an ETT with subglottic secretion drainage is cumbersome and risky8; (2) difficulty in predicting the duration of mechanical ventilation (ETT with subglottic secretion drainage is most beneficial for patients intubated for $>48 \mathrm{~h})^{8}$; (3) the suction port can be occluded by secretions; and (4) the suction port may get occluded by tracheal mucosa, which results in mucosal damage and failure to drain secretions. Seguin et $\mathrm{al}^{9}$ recently reported that the incidence of tracheal mucosal damage was $17 \%$ in the intermittent suctioning group and $27 \%$ in the continuous suctioning group with subglottic secretion drainage utilization.

See the Original Study on Page 372

To overcome these technological shortcomings, an innovative maneuver was recently proposed to clear subglottic secretions. ${ }^{10}$ This maneuver requires a minimum of 2 experienced clinicians, one to produce a rapid flow by squeezing a resuscitation bag at the beginning of the patient's expiration, the other to manage the ETT cuff deflation-re-inflation. Although the maneuver seems to be safe and effective, its success relies on practitioner skill and understanding of the mechanism. The involvement of 2 clinicians makes it difficult to accomplish in a busy ICU.

Zanella et $\mathrm{al}^{2}$ assessed a prototype device that automatically manipulates the ETT cuff in synchronization with the ventilator breath that is designed to remove secretions on both sides of the ETT cuff. Instead of manually squeezing a resuscitation bag, the device, based on predetermined criteria, helps to produce an artificial cough. This innovative design incorporates the collaboration between lung expansion and cuff management, which significantly reduces the complexity of the maneuver and makes it possible to be used at the bedside by a single person. The large pressure gradient between the airway and oral cavity generates a rapid flow, which simulates a cough to move secretions from the airways to the oral cavity. ${ }^{2,10}$ The secretions located in the central airway, around the tip of the ETT and cuff, and below and above the cuff, are expelled by the effective artificial cough. 
Previous studies mainly focused on secretions above the cuff;,4-10 however, Zanella et $\mathrm{al}^{2}$ did not investigate the clearance efficiency on just these subglottic secretions. Instead, they sought to understand how this maneuver impacted secretions below the cuff, as previously mentioned. They found that $63-80 \%$ of synthetic sputum below the ETT was removed by 5 artificial cough maneuvers during the in vitro study, and all the radiopaque tantalum disks below the cuff were removed within 7 minutes in a swine model. ${ }^{2}$

In another recent study, Volpe et al ${ }^{11}$ found that the key factor to move mucus in the trachea, in an intubated model, was the difference between peak inspiratory and expiratory flows. They found that mucus clearance was ineffective if the peak inspiratory flow was higher than the peak expiratory flow. ${ }^{11}$ The significant difference between the models used in studies by Zanella et $\mathrm{al}^{2}$ and Volpe et $\mathrm{al}^{11}$ was cuff deflation, in which the expiratory resistance in the model by Zanella et $\mathrm{al}^{2}$ decreased enormously, which allowed for a much higher expiratory flow in the artificial cough maneuver. In addition, they found that the highest peak expiratory flow produced by the low compliance, low resistance model generated the highest clearance efficiency among the 3 models. ${ }^{2}$

A reasonable concern regarding this maneuver is that airway pressure might decrease during the period of cuff deflation. Zanella et $\mathrm{al}^{2}$ reported that, during cuff deflation, the average tracheal pressure decreased to a minimum of $19.1 \pm 3.5 \mathrm{~cm} \mathrm{H}_{2} \mathrm{O}\left(12.9-27.2 \mathrm{~cm} \mathrm{H}_{2} \mathrm{O}\right){ }^{2}$ This pressure may be sufficient to maintain alveolar recruitment in many patients who are intubated; however, it may be problematic in patients who require high levels of PEEP.

As pointed out by the authors, secretion clearance and suctioning are performed when there are signs of secretion retention (audible or visible secretions, breath sounds, hypoxemia, or acute respiratory distress). ${ }^{12}$ Also, they noted that suctioning via ETT was invasive and could be unpleasant for the patient. This study offered a new concept of secretion clearance that may lead to a more proactive management of secretions that reduces the complications associated with ETT suctioning. This method seems promising as a way to reduce or replace ETT suctioning, but further clinical studies are needed to examine this potential.

$$
\begin{array}{r}
\text { Jie Li } \\
\text { J Brady Scott } \\
\text { Division of Respiratory Care } \\
\text { Department Cardiopulmonary Sciences } \\
\text { Rush University Medical Center } \\
\text { Chicago, Illinois } \\
\text { Jian Luo } \\
\text { Pulmonary and Critical Care Medicine } \\
\text { Hospital and West China School of Medicine } \\
\text { Sichuan University } \\
\text { Chengdu, China }
\end{array}
$$
West China Hospital and West China School of Medicine

\author{
Huaping Dai \\ Chen Wang \\ Pulmonary and Critical Care Medicine \\ China-Japan Friendship Hospital \\ National Clinical Research Center for Respiratory Diseases \\ Institute of Respiratory Medicine \\ Chinese Academy of Medical Sciences \\ Beijing, China
}

\section{REFERENCES}

1. Nseir S, Zerimech F, Jaillette E, Artru F, Balduyck M. Microaspiration in intubated critically ill patients: diagnosis and prevention. Infect Disord Drug Targets 2011;11(4):413-423.

2. Zanella A, Florio G, Rezoagli E, Pastore M, Cadringer P, Biancolilli $\mathrm{O}$, et al. An artificial cough maneuver to remove secretions from below the endotracheal tube cuff. Respir Care 2019;64(4):372-383.

3. Torres A, Niederman MS, Chastre J, Ewig S, Fernandez-Vandellos $\mathrm{P}$, Hanberger $\mathrm{H}$, et al. International ERS/ESICM/ESCMID/ALAT guidelines for the management of hospital-acquired pneumonia and ventilator-associated pneumonia: Guidelines for the management of hospital- acquired pneumonia (HAP) /ventilator-associated pneumonia (VAP) of the European Respiratory Society (ERS), European Society of Intensive Care Medicine (ESICM), European Society of Clinical Microbiology and Infectious Diseases (ESCMID) and Asociación Latinoamericana del Tórax (ALAT). Eur Respir J. 2017; 50(3). pii: 1700582.

4. Li Bassi G, Senussi T, Aguilera Xiol E. Prevention of ventilatorassociated pneumonia. Curr Opin Infect Dis 2017;30(2):214-220.

5. Bassi GL, Xiol EA, Pagliara F, Hua Y, Torres A. Body position and ventilator-associated pneumonia prevention. Semin Respir Crit Care Med 2017;38(3):371-380.

6. Sánchez-Ramírez C, Hípola-Escalada S, Cabrera-Santana M, Hernández-Viera MA, Caipe-Balcázar L, Saavedra P, et al. Long-term use of selective digestive decontamination in an ICU highly endemic for bacterial resistance. Crit Care 2018;22(1):141.

7. Landelle C, Nocquet Boyer V, Abbas M, Genevois E, Abidi N, Naimo $S$, et al. Impact of a multifaceted prevention program on ventilator-associated pneumonia including selective oropharyngeal decontamination. Intensive Care Med 2018;44(11):17771786.

8. Rouzé A, Martin-Loeches I, Nseir S. Airway devices in ventilatorassociated pneumonia pathogenesis and prevention. Clin Chest Med 2018;39(4):775-783.

9. Seguin P, Perrichet H, Pabic EL, Launey Y, Tiercin M, Corre R, et al. Effect of continuous versus intermittent subglottic suctioning on tracheal mucosa by the Mallinckrodt TaperGuard evac oral tracheal tube in intensive care unit ventilated patients: a prospective randomized study. Indian J Crit Care Med 2018;22(1):1-4.

10. Li J, Zong Y, Zhou Q, Dai H, Wang C. Evaluation of the safety and effectiveness of the rapid flow expulsion maneuver to clear subglottic secretions in vitro and in vivo. Respir Care 2017;62(8):10071013.

11. Volpe MS, Naves JM, Ribeiro GG, Ruas G, Tucci MR. Effects of manual hyperinflation, clinical practice versus expert recommendation, on displacement of mucus simulant: A laboratory study. PLoS One 2018;13(2):e0191787.

12. Gilder E, Parke RL, Jull A Australian and New Zealand Intensive Care Society Clinical Trials Group and The George Institute for Global Health. Endotracheal suction in intensive care: a point prevalence study of current practice in New Zealand and Australia. Aust Crit Care 2019;32(2):112-115. 